be interesting to those who are keen on ocean racing, to hear about some of the dodges (certainly not new to them) used on board Artica II :

(a) A gnomon pin (about two inches long) had been welded in the centre of the compass rose: when the Sun was low and the boat sufficiently steady the shadow of this needle enabled us to have very good compass checks.

(b) Tables H.O. 249 (AP 3270 ) were normally used for star fixes, because of the advantages they offer not only in the reduction of sights but especially in the identification of stars. When the altitude and azimuth of the stars are accurately known and the sextant set, the stars can be picked up on the horizon, and sights are possible when sea conditions would make it impossible to bring the stars down to the horizon.

(c) Three well-rated watches were used, so that they could be controlled by their daily differences. This old system proved most useful when timesignals were not received for several days: one might gather from this that as soon as conditions become 'old'-such as not having time signals for days - the 'old' systems prove to be quite up to date!

(d) Although our charts fulfilled all our needs both in the open sea and in sight of land, it was found convenient to use plotting sheets on which to draw a suitable scale map for landfalls.

I would like to end these few remarks by suggesting an idea to instrument makers in the form of a device enabling the micrometer screw to be operated with the hand that holds the sextant, for instance a flexible transmission attached to the sextant handle and operated by the right thumb. This would leave, in the final and most delicate moments, the left arm completely free for keeping one's balance by holding on to a shroud, a stay, or anything else. I think such a device could considerably help navigators fight their biggest enemy in star shooting from small boats-the instability of the platform - and would be most heartily welcomed by them.

\title{
The Beaufort Scale
}

$$
\text { from E. L. Delmar-Morgan }
$$

I was particularly interested in Commander C. E. N. Frankcom's note on the Beaufort wind scale at the end of the article by the Hydrographer of the Navy on Admiral Sir Francis Beaufort (this Journal, 11, 266).

Commander Frankcom states that from time to time attempts have been made to abandon the Beaufort scale and adopt some other form of scale but that efforts to do this have failed. Efforts to improve on or change the form of the Beaufort scale are, in my opinion, likely to continue to fail for the very good reason that the existing scale is almost flawless mathematically. I touched upon this subject in an article entitled 'Selecting Equipment by Numbers', in Yachting World in March I 955. The general theme of what I then wrote is as follows:

The attached table shows the four principal series of Preferred Numbers. The first use of the Preferred Number series, or Renard series, took place in France 
PREFERRED NUMBERS. PRINCIPAL SERIES

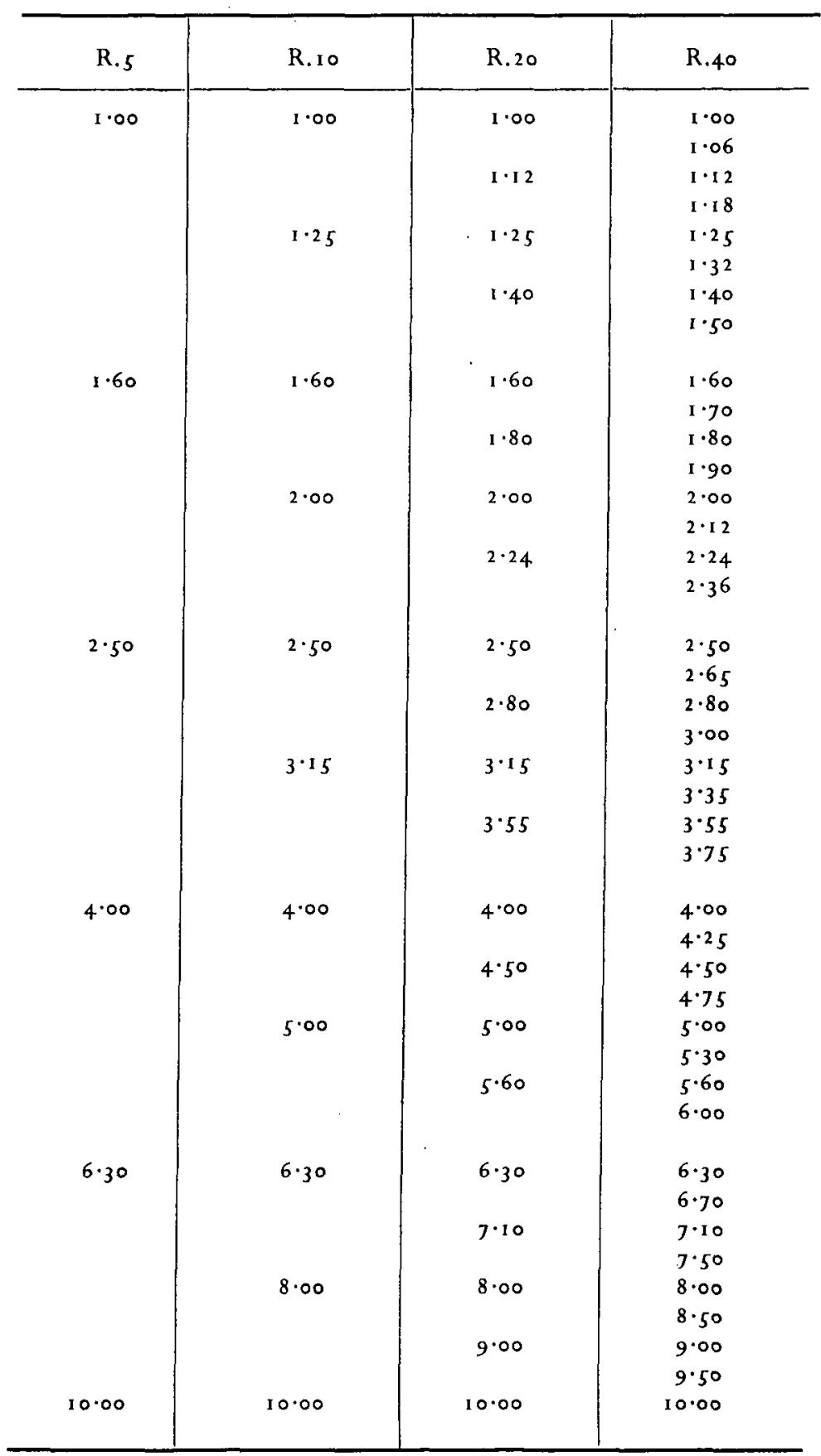


at the end of the nineteenth century; it was in fact Engineer Captain Charles Renard who developed them in trying to find an original series of thicknesses of ropes in connection with the construction of balloons. These numbers are merely convenient series of numbers in geometric progression based on the 5 th, roth, 2 oth or 4 oth roots of 10 (i.e. antilog $1 / 5$, antilog $2 / 5$, antilog $3 / 5$, and so on, based on the $5^{\text {th }}$ root of 10 ). These numbers have been found to have various convenient properties and enable any standard for length, size, weight or power, which is required to be in ascending or descending order of magnitude, to be chosen with facility to give step increments of $3,6,9,12,18,25$, 40,60 and 100 per cent. (These are the standard percentage increments; others are possible.) Another common series is that based on 2 (i.e. 2, 4, 6, 8 , I6, \&c.) and this too is a Preferred Number series.

The foregoing very brief description of Preferred Numbers is adequate for our purpose here, but the whole story is lucidly set out in B.S. 1638: 1950-Report on Selection of Ranges of Types and Sizes, and B.S. 2045: 1953-Preferred Numbers.

Now if we look at the Beaufort scale in the light of what has just been said and it will be seen how closely the figures chosen by Admiral Beaufort tally with the figures in the R.20 column with a few R.40 in addition. The greatest disparity on a percentage basis is 24 knots instead of the Preferred Number 25 (I should remark that the decimal point must be moved in order to make the comparison).

With the table of Preferred Numbers before us we could perhaps make one or two small modifications to produce smoothing, and change 'about 65 knots' to, say, 'about 67 knots'; but the scale is almost perfect as it is and that, I submit, is the reason why attempts to modify it have failed.

BEAUFORT WंIND SCALE

\begin{tabular}{c|l|c}
\hline $\begin{array}{c}\text { Beaufort no. } \\
\text { force }\end{array}$ & Description of wind & $\begin{array}{c}\text { Average velocity } \\
\text { in nautical miles } \\
\text { per hour }\end{array}$ \\
\hline 0 & Calm & \\
1 & Light air & 0 \\
2 & Light breeze & 2 \\
3 & Gentle breeze & 5 \\
4 & Moderate breeze & 9 \\
5 & Fresh breeze & 14 \\
6 & Strong breeze & 24 \\
7 & Near gale & 30 \\
8 & Gale & 37 \\
9 & Strong gale & 44 \\
I0 & Storm & 52 \\
I & Violent storm & 60 \\
1 2 & Hurricane & About 65 \\
\hline
\end{tabular}

